resonance imaging. Burns 1996;22:420-1.

2. Karoo RO, Whitaker IS, Garrido A, et al. Full-thickness burns following magnetic resonance imaging: a discussion of the dangers and safety suggestions. Plast Reconstr Surg 2004; 114:1344-5.

3. Balanis CA. Antenna theory: analysis and design. Hoboken: Wiley Interscience; 2005.

\section{Primary Necrotizing Fasciitis of the Breast in an Untreated Patient with Diabetes}

Jeong Hwan Lee, Yun Sub Lim, Nam Gyun Kim, Kyung Suk Lee, Jun Sik Kim

Department of Plastic and Reconstructive Surgery, Institute of Health Sciences, Gyeongsang National University Hospital, Gyeongsang National University School of Medicine, Jinju, Korea

Correspondence: Jun Sik Kim

Department of Plastic and Reconstructive Surgery, Institute of Health Science, Gyeongsang National University College of Medicine, Gyeongsang National

University Hospital, 79 Gangnam-ro, Jinju 52727, Korea

Tel: +82-55-750-8647, Fax: +82-55-758-6240

E-mail:kjuns@hanmail.net

This article was presented as a poster at the 6 th Research and Reconstructive Forum on April 4-8, 2016 in Daegu, Korea.

No potential conflict of interest relevant to this article was reported.

Received: 31 Mar 2016• Revised: 29 Jun $2016 \bullet$ Accepted: 5 Jul 2016 pISSN: 2234-6163 • elSSN: 2234-6171

https://doi.org/10.5999/aps.2016.43.6.613

Arch Plast Surg 2016;43:613-614

Copyright (C) 2016 The Korean Society of Plastic and Reconstructive Surgeons This is an Open Access article distributed under the terms of the Creative Commons Attribution Non-Commercial License (http://creativecommons.org/licenses/by-nc/4.0/) Attribution Non-Commercial License (http://creativecommons.org/licenses/by-nc/4.0/)
which permits unrestricted non-commercial use, distribution, and reproduction in any medium, provided the original work is properly cited.

Necrotizing fasciitis (NF) is a soft tissue infection that can be fatal. Diagnosis may be delayed because NF is easily misdiagnosed as an abscess or cellulitis [1]. It is commonly found in the extremities, perineum, and abdominal wall, but rarely in the breast. NF of the breast can be caused by previous surgery (e.g., mastectomy, implant augmentation) or trauma [2]. In this report, we present a rare case of primary NF of the breast in a patient with untreated diabetes.

A 31-year-old female patient presented to the emergency department with a 5-day history of skin color change, pain, and swelling in the left breast. The patient had been diagnosed with diabetes 6 years before, and had discontinued insulin treatment for the last 2 years. The patient reported no trauma and nor any previous surgical procedure on the breast, which was markedly swollen and erythematous. A patchy, purple and black eschar was observed in the medial area of the left breast (Fig. 1). Chest enhanced computed tomography revealed a fluid pocket approximately $9 \mathrm{~cm}$ in diameter with an air bubble in the left breast (Fig. 2). An emergency operation was performed to debride the necrotic skin and soft tissue. The disease was diagnosed as NF. After several debridements, the defected area was covered by a latissimus dorsi musculocutaneous flap and a fullthickness skin graft (Fig. 3). There were no complications, and the patient was discharged after two weeks.

We experienced and report here a case in a young female patient of primary NF of the left breast that was successfully treated and reconstructed. To our knowledge, this is a rare case of a patient without previous trauma that spontaneously developed NF.

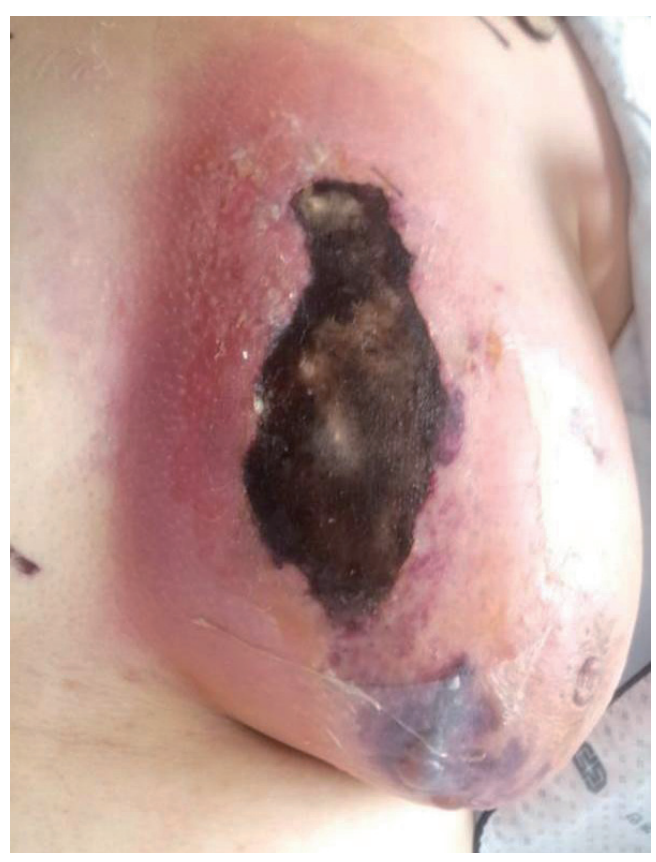

Fig. 1.

Initial photograph in the emergency department. A 31-year-old female patient presented to the emergency department with left breast skin color change, pain, swelling, and discharge.

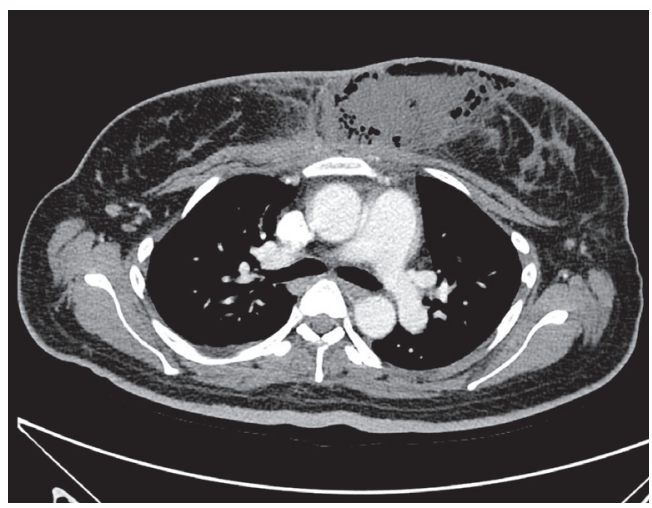

Fig. 2.

Initial chest ECT of the patient. There was an approximately 9-cm fluid pocket with an air bubble in the left breast, with edematous swelling and overlying skin thickening. ECT, enhanced computed tomography. 
Fig. 3.

Preoperative and postoperative photos of the patient. (A) After several debridements, extended defects remained through the skin and soft tissue in the left

breast. (B) The defects were covered with a latissimus dorsi musculocutaneous flap and a full-thickness skin graft.

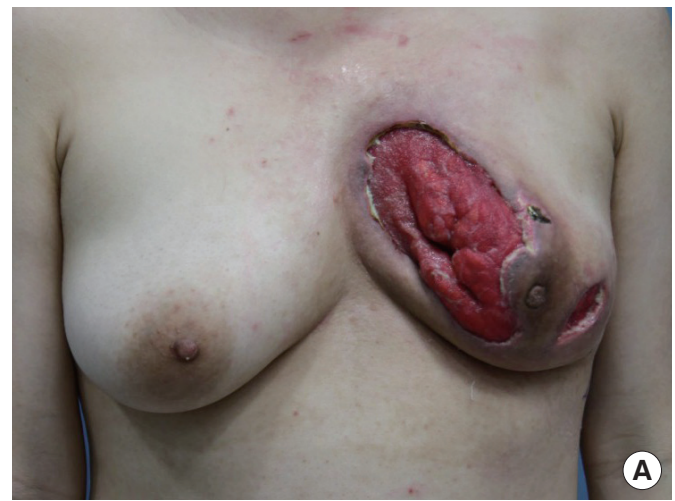

\section{References}

1. Edlich RF, Cross CL, Dahlstrom JJ, et al. Modern concepts of the diagnosis and treatment of necrotizing fasciitis. J Emerg Med 2010;39:261-5.

2. Yang B, Connolly S, Ball W. Necrotising fasciitis of the breast: a rare primary case with conservation of the nipple and literature review. JPRAS Open 2015;6:15-9.

\section{A Band-Like Neck Scar Contracture after Bilateral Axillo-Breast Approach Robotic Thyroidectomy}

Do Hoon Kwak, Woo Seob Kim, Han Koo Kim, Tae Hui Bae

Department of Plastic and Reconstructive Surgery, Chung-Ang University Medical School, Seoul, Korea

\section{Correspondence: Woo Seob Kim}

Department of Plastic and Reconstructive Surgery, Chung-Ang University Medical School, 102 Heukseok-ro, Dongjak-gu, Seoul 06973, Korea Tel: +82-2-6299-1615, Fax: +82-2-6298-1866

E-mail:kimws@cau.ac.kr

No potential conflict of interest relevant to this article was reported.

Received: 17 Mar 2016 • Revised: 7 Jul 2016• Accepted: 12 Jul 2016 pISSN: 2234-6163・ elSSN: 2234-6171

https://doi.org/10.5999/aps.2016.43.6.614

Arch Plast Surg 2016:43:614-615

Copyright (C) 2016 The Korean Society of Plastic and Reconstructive Surgeon This is an Open Access article distributed under the terms of the Creative Commons Attribution Non-Commercial License (http://creativecommons.org/licenses/by-nc/4.0/) which permits unrestricted non-commercial use, distribution, and reproduction in any medium, provided the original work is properly cited.

Recently, robotic surgical operations have been performed in many surgical areas because the oncologic results are almost the same as conventional surgery but robotic surgery requires an incision of only a few centimeters to approach the surgical site

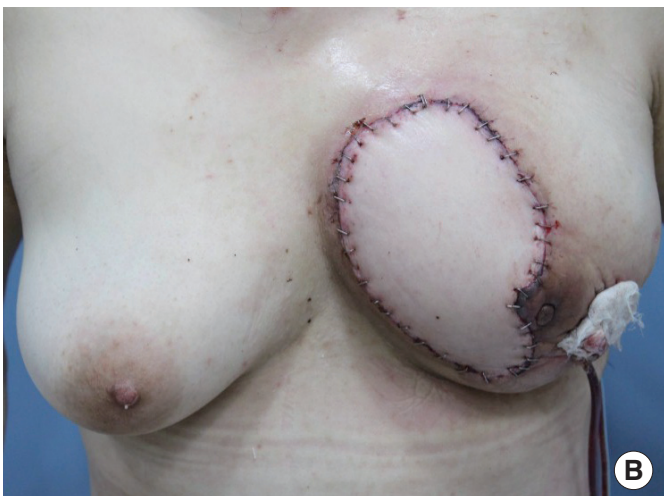

[1]. Thus, many patients with thyroid cancer choose robotic surgery because of reduced scarring [2].

A 39-year-old female patient with thyroid cancer of the right lobe underwent robotic thyroidectomy via a bilateral axillo-breast approach, both axillary and mammillary [3]. After 7 months, she felt tightness in her chest and neck. She was diagnosed with major depressive disorder and panic disorder in relation to these symptoms. A band-like lesion appeared 1 year after thyroidectomy (Fig. 1). The chest and neck were connected with band-like scar tissue. During swallowing, the chest and neck moved simultaneously.

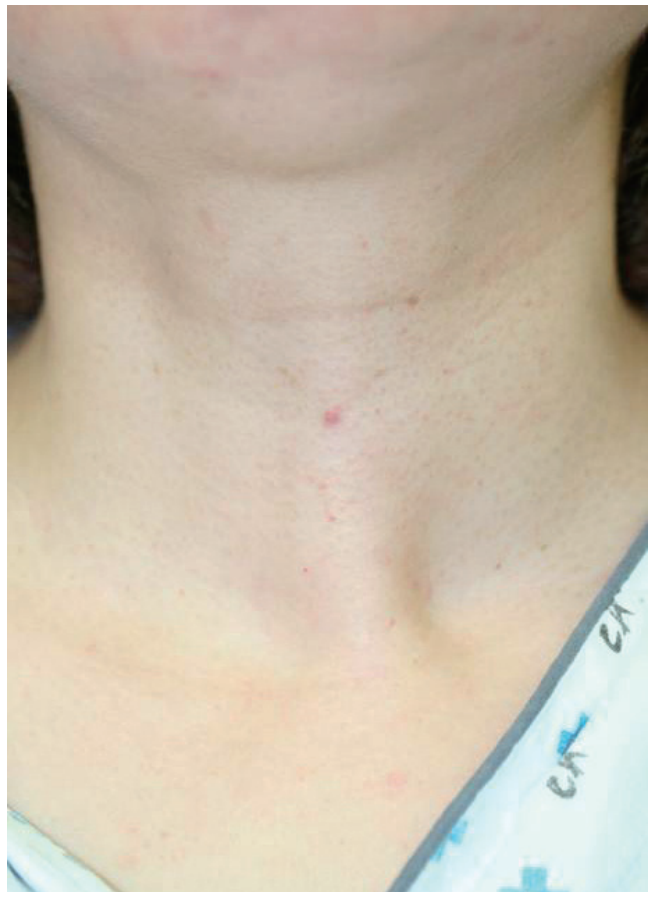

Fig. 1.

One year after thyroidectomy, band-like scar tissue appeared and the patient experienced discomfort of the neck and chest. The neck and chest moved simultaneously during swallowing. 